Pacific Journal of Mathematics

ON COMPARABLE MEANS

id Shisha and Gerald Thomas Cargo 


\section{ON COMPARABLE MEANS}

\section{O. Shisha and G. T. Cargo}

1. Let $-\infty<a<b<\infty$, and let $\Phi$ denote the set of all functions, continuous and strictly monotone in $[a, b]$. For every $\varphi \in \Phi$, every positive integer $n$, every $x_{1}, x_{2}, \cdots, x_{n}$ of $[a, b]$, and every positive $q_{1}, q_{2}, \cdots, q_{n}$ with $\sum_{\nu=1}^{n} q_{\nu}=1$, we consider the mean

$$
M_{\varphi}\left(x_{1}, x_{2}, \cdots, x_{n} \mid q_{1}, q_{2}, \cdots, q_{n}\right)=\varphi^{-1}\left(\sum_{\nu=1}^{n} q_{\nu} \varphi\left(x_{\nu}\right)\right) .
$$

Let $\psi$ and $\chi$ be elements of $\Phi$. We write

$$
M_{\psi} \leqq M_{\text {x }}
$$

if and only if the inequality $M_{\psi}\left(x_{1}, x_{2}, \cdots, x_{n} \mid q_{1}, q_{2}, \cdots, q_{n}\right) \leqq$ $M_{x}\left(x_{1}, x_{2}, \cdots, x_{n} \mid q_{1}, q_{2}, \cdots, q_{n}\right)$ holds for every $n \geqq 1$, every $x_{1}, x_{2}, \cdots$, $x_{n}$ of $[a, b]$, and every positive $q_{1}, q_{2}, \cdots, q_{n}$ with $\sum_{\nu=1}^{n} q_{\nu}=1$.

A well-known necessary and sufficient condition for (1) to hold is that $\chi\left(\psi^{-1}(x)\right)$ be convex in $[\psi(a), \psi(b)]$ (or $[\psi(b), \psi(a)]$ ) if $\chi$ is increasing, and that $\chi\left(\psi^{-1}(x)\right)$ be concave there if $\chi$ is decreasing.

It is not difficult to see that (1) holds if and only if $M_{\psi}\left(x_{1}, x_{2} \mid q_{1}, q_{2}\right) \leqq$ $M_{x}\left(x_{1}, x_{2} \mid q_{1}, q_{2}\right)$ for every $x_{1}, x_{2}$ of $[a, b]$ and every positive $q_{1}, q_{2}$ with $q_{1}+q_{2}=1$, which in turn holds if and only if $M_{\psi}\left(x_{1}, x_{2} \mid 1 / 2,1 / 2\right) \leqq$ $M_{\mathrm{x}}\left(x_{1}, x_{2} \mid 1 / 2,1 / 2\right)$ for every $x_{1}, x_{2}$ of $[a, b]$.

Similarly, we write

$$
M_{\nu^{\prime}}<M_{\text {x }}
$$

if and only if the inequality

$$
M_{\gamma}\left(x_{1}, x_{2}, \cdots, x_{n} \mid q_{1}, q_{2} \cdots, q_{n}\right)<M_{x}\left(x_{1}, x_{2}, \cdots, x_{n} \mid q_{1}, q_{2} \cdots, q_{n}\right)
$$

holds for every $n \geqq 2$, every $x_{1}, x_{2}, \cdots, x_{n}$ (not all equal) of $[a, b]$, and every positive $q_{1}, q_{2}, \cdots, q_{n}$ with $\sum_{\nu=1}^{n} q_{\nu}=1$. A necessary and sufficient condition for (2) to hold is that $\chi\left(\psi^{-1}(x)\right)$ be strictly convex in $[\psi(a), \psi(b)]$ (or $[\psi(b), \psi(a)]$ ) if $\chi$ is increasing, and that $\chi\left(\psi^{-1}(x)\right.$ ) be strictly concave there if $\chi$ is decreasing. Also, (2) holds if and only if $M_{\psi}\left(x_{1}, x_{2} \mid q_{1}, q_{2}\right)<M_{x}\left(x_{1}, x_{2} \mid q_{1}, q_{2}\right)$ for every $x_{1}, x_{2}\left(\neq x_{1}\right)$ of $[a, b]$ and every positive $q_{1}, q_{2}$ with $q_{1}+q_{2}=1$, which in turn holds if and only if $M_{\psi}\left(x_{1}, x_{2} \mid 1 / 2,1 / 2\right)<M_{\chi}\left(x_{1}, x_{2} \mid 1 / 2,1 / 2\right)$ for every $x_{1}$ and $x_{2}\left(\neq x_{1}\right)$ of $[a, b]$.

2. In this paper we give simple criteria for the validity of

Received December 30, 1963. The work of the second author was supported by the National Science Foundation through grant NSF-GP 1086. 
and of (2), and then we give a few applications.

Theorem 1. Let $\psi$ and $\chi$ be elements of $\Phi$ differentiable in $(a, b)$, and let $\psi^{\prime} \neq 0$ there. A necessary and sufficient condition for (1) to hold is that $\chi^{\prime} / \psi^{\prime}$ be nondecreasing in $(a, b)$ if $\psi$ and $\chi$ are monotone in the same sense, and that $\chi^{\prime} / \psi^{\prime}$ be nonincreasing there if $\psi$ and $\chi$ are monotone in opposite senses.

Proof. Consider the function $u(x) \equiv \chi\left(\psi^{-1}(x)\right)$. Let $J$ denote the open interval joining $\psi(a)$ to $\psi(b)$, and let $\bar{J}$ be the closure of $J$. For every $\xi \in J$, we have

$$
u^{\prime}(\xi)=\chi^{\prime}\left(\psi^{-1}(\xi)\right) / \psi^{\prime}\left(\psi^{-1}(\xi)\right) .
$$

Suppose that $\psi$ and $\chi$ are monotone in the same sense. Then (1) holds if and only if $u(x)$ is convex in $\bar{J}$ in case $\chi$ increases, and if and only if $u(x)$ is concave there in case $\chi$ decreases. So (1) holds if and only if $u^{\prime}(x)$ is nondecreasing in $J$ in case $\psi$ increases, and if and only if $u^{\prime}(x)$ is nonincreasing there in case $\psi$ decreases. From this, with the aid of (3), one easily infers that (1) is equivalent to $\chi^{\prime} / \psi^{\prime}$ being nondecreasing in $(a, b)$. Similariy one shows that (1) is equivalent to $\chi^{\prime} / \psi^{\prime}$ being nonincreasing in $(a, b)$, if $\psi$ and $\chi$ are monotone in opposite senses.

One can modify Theorem 1 by replacing in it (1) by (2), "nondecreasing" by "strictly increasing," and "nonincreasing" by "strictly decreasing."

3. Given a function $\psi$, one may construct by means of RiemannStieltjes integrals functions $\chi$ such that $M_{\psi} \leqq M_{\mathrm{x}}$. In fact, we have the following

THEOREM 2. Let $\psi$ be a real function, continuous in $[a, b]$ and differentiable in $(a, b)$. Let $m(x)$ be nondecreasing or nonincreasing in $[a, b]$, continuous in $(a, b)$, and suppose $m(x) \psi^{\prime}(x) \neq 0$ throughout $(a, b)$. Let $C$ be a real constant, and for every $x \in[a, b]$ let

$$
\chi(x)=C+\int_{a}^{x} m(t) d \psi(t) .
$$

Then $\psi$ and $\chi$ belong to $\Phi$. If $m(x)$ is positive in $(a, b)$ and nondecreasing in $[a, b]$, or negative in $(a, b)$ and nonincreasing in $[a, b]$, then $M_{\psi} \leqq M_{\mathrm{x}}$. Otherwise, $M_{\mathrm{x}} \leqq M_{\psi}$.

Proof. Since $\psi^{\prime} \neq 0$ in $(a, b)$, by a well known property of the derivative, $\psi^{\prime}$ is either positive throughout $(a, b)$, or negative through- 
out $(a, b)$. Thus $\psi$ is strictly monotone in $[a, b]$. Also, by well-known properties of the Riemann-Stieltjes integral, $\chi$ is continuous in $[a, b]$, and $\chi^{\prime}(x)=m(x) \psi^{\prime}(x)$ throughout $(a, b)$ (and so $\chi$ is strictly monotone in $[a, b])$. If $m(x)$ is positive in $(a, b)$ and nondecreasing in $[a, b]$, then $\psi$ and $\chi$ are monotone in the same sense in $[a, b], \chi^{\prime} / \psi^{\prime}$ is nondecreasing in $(a, b)$, and hence by Theorem $1, M_{\psi} \leqq M_{\times}$. Similarly the rest of Theorem 2 follows.

Theorem 2 can be modified by replacing in it "nondecreasing" by "strictly increasing," "nonincreasing" by "strictly decreasing," " $M_{\psi} \leqq M_{x}$ " by " $M_{\psi}<M_{\chi}$ " "and " $M_{x} \leqq M_{\psi}$ " by " $M_{x}<M_{\psi}$."

\section{A converse of Theorem 2 is the following}

THEOREM 3. Let $\psi$ and $\chi$ be elements of $\Phi$ differentiable in $(a, b)$, and suppose $\psi^{\prime} \neq 0$ there. Suppose, furthermore, that $M_{\psi} \leqq M_{\times}$. Then there exists a function $m(x)$, nondecreasing in $(a, b)$ if $\psi$ and $\chi$ are monotone in the same sense, and nonincreasing there if $\psi$ and $\chi$ are monotone in opposite senses, such that throughout $[a, b]$

$$
\chi(x)=\chi(a)+\int_{a}^{x} m(t) \psi^{\prime}(t) d t \quad \text { (a Lebesgue integral) . }
$$

Proof. For every $x \in(a, b)$, let $m(x)=\chi^{\prime}(x) / \psi^{\prime}(x)$. By Theorem 1, $m(x)$ has the monotonicity property steated in Theorem 3. Now for every $x \in[a, b]$

$$
\chi(x)-\chi(a)=\int_{a}^{x} \chi^{\prime}(t) d t=\int_{a}^{x} m(t) \psi^{\prime}(t) d t
$$

(cf. [5], Theorems 269 (p. 188) and 264 (p. 183)).

REMARK. Observe that the integral in (4) can be written, under appropriate conditions, as a Riemman-Stieltjes integral: $\int_{a}^{x} m(t) d \psi(t)$. [Cf. loc. cit, Theorem 322.1 (p. 254), and 322 (p. 253)].

Theorem 3 remains valid if we replace in it " $M_{\psi} \leqq M_{x}$ " by " $M_{\psi}<M_{\chi}$ " "nondecreasing" by "strictly increasing," and "nonincreasing" by "strictly decreasing."

5. It is known that if the end-point $a$ is positive and $r<s$, $r s \neq 0$, then $M_{x^{r}}<M_{x}$, and $M_{x^{-|r|}}<M_{\log x}<M_{x^{|r|}}$. Consequently, if $a>0$ then for every real $r(\neq 0,1), M_{(x)^{\prime}}<M_{x}$, and $M_{(\log x)^{\prime}},<M_{\log x}$. The question thus arises: Under what conditions on a function $\varphi$ does one have $M_{\varphi^{\prime}}<M_{\varphi}$ (or $M_{\varphi^{\prime}} \leqq M_{\varphi}$ ) ?

THEOREM 4. A necessary and sufficient condition for a real 
function $\varphi$ to fulfill the conditions $(\alpha)-(\gamma)$ below is that $\varphi(x)$ should be (throughout $[a, b])$ of one of the forms $A+\int_{a}^{x} \exp C(t) d t, A-$ $\int_{a}^{x} \exp C(t) d t, A+\int_{a}^{x} \exp \{-C(t)\} d t, A-\int_{a}^{x} \exp \{-C(t)\} d t$, where $A$ is a real number, and $C(t)$ is a function, continuous and convex in $[a, b]$, differentiable in $(a, b)$, and satisfying there $C^{\prime}(x)<0$.

( $\alpha$ ) $\varphi$ is twice differentiable in $(a, b), \varphi^{\prime}(a)$ and $\varphi^{\prime}(b)$ exist as right and left hand derivatives, respectively, $\varphi^{\prime}(a) \varphi^{\prime}(b) \neq 0$, and $\varphi^{\prime}$ is continuous in $[a, b]$.

( $\beta$ ) $\varphi^{\prime} \varphi^{\prime \prime} \neq 0$ throughout $(a, b)$ (and hence $\varphi$ and $\varphi^{\prime}$ are strictly monotone in $[a, b])$.

( $) \quad M_{\varphi^{\prime}} \leqq M_{\varphi}$.

\section{Proof.}

Necessity. By Theorem 1, $\varphi^{\prime} / \varphi^{\prime \prime}$ is either positive and nondecreasing in $(a, b)$, or negative and nonincreasing there. Thus, $\varphi^{\prime \prime} / \varphi^{\prime}$ is either positive and nonnincreasing in $(a, b)$, or negative and nondecreasing there. In the first case we set $C(x)=-\log \left|\varphi^{\prime}(x)\right|$ (in $[a, b]$ ). Then $C(x)$ is continuous in $[a, b]$ and $C^{\prime}(x)<0$ in $(a, b)$. Also $C^{\prime}(x)$ is nondecreasing in $(a, b)$, and, therefore, $C(x)$ is convex in $[a, b]$. Either for every $x \in[a, b], \varphi(x)=\varphi(a)+\int_{a}^{x} \exp \{-C(t)\} d t$, or for every $x \in[a, b]$, $\varphi(x)=\varphi(a)-\int_{a}^{x} \exp \{-C(t)\} d t$. In the second case, we set $C(x)=$ $\log \left|\varphi^{\prime}(x)\right|$ (in $[a, b]$ ). Then $C(x)$ is continuous in $[a, b], C^{\prime}(x)<0$ in $(a, b)$, and, again, $C(x)$ is convex in $[a, b]$. Either for every $x \in[a, b]$, $\varphi(x)=\varphi(a)+\int_{a}^{x} \exp C(t) d t$, of for every $x \in[a, b], \quad \varphi(x)=\varphi(a)-$ $\int_{a}^{x} \exp C(t) d t$

Sufficiency. $(\alpha)$ and $(\beta)$ clearly hold. Also, by the convexity of $C(t), C^{\prime}(t)$ is nondecreasing in $(a, b)$. Now, either throughout $(a, b)$, $\varphi^{\prime} / \varphi^{\prime \prime}=\left\{C^{\prime}(t)\right\}^{-1}$, or throughout $(a, b), \varphi^{\prime} / \varphi^{\prime \prime}=-\left\{C^{\prime}(t)\right\}^{-1}$. In the first case, $\varphi^{\prime}$ and $\varphi$ are monotone in opposite senses, and $\varphi^{\prime} / \varphi^{\prime \prime}$ is nonincreasing in $(a, b)$. In the second case, $\varphi^{\prime}$ and $\varphi$ are monotone in the same sense, and $\varphi^{\prime} / \varphi^{\prime \prime}$ is nondecreasing in $(a, b)$. In either case, by Theorem $1, M_{\varphi^{\prime}} \leqq M_{\varphi}$.

Theorem 4 can be modified by replacing in it "convex" by "strictly convex," and " $M_{\varphi^{\prime}} \leqq M_{\varphi}$ " by " $M_{\varphi^{\prime}}<M_{\varphi}$."

THEOREM 5. Let $\varphi$ be strictly monotone in $[a, b]$ and three-times differentiable in $(a, b)$. Let $\phi^{\prime}$ be continuous in $[a, b]$ (where $\varphi^{\prime}(a)$ 
and $\varphi^{\prime}(b)$ are right and left hand derivatives, respectively). Let $\varphi^{\prime \prime} \neq 0$ throughout $(a, b)$. A necessary and sufficient condition for $M_{\varphi^{\prime}} \leqq M_{\varphi}$ to hold is that $\varphi^{\prime \prime 2} \geqq \varphi^{\prime} \varphi^{\prime \prime \prime}$ throughout $(a, b)$ if $\varphi^{\prime}$ and $\varphi$ are monotone in the same sense, and that $\varphi^{\prime \prime 2} \leqq \varphi^{\prime} \varphi^{\prime \prime \prime}$ throughout $(a, b)$ if $\varphi^{\prime}$ and $\varphi$ are monotone in opposite senses.

Theorem 5 follows easily from Theorem 1 by considering the derivative of $\varphi^{\prime} / \varphi^{\prime \prime}$.

Similarly, under the hypotheses of Theorem 5, $M_{\varphi^{\prime}}<M_{\varphi}$ holds, if $\varphi^{\prime \prime 2}>\varphi^{\prime} \varphi^{\prime \prime \prime}$ throughout $(a, b)$ and $\varphi$ and $\varphi^{\prime}$ are monotone in the same sense, and also if $\varphi^{\prime \prime 2}<\varphi^{\prime} \varphi^{\prime \prime \prime}$ throughout $(a, b)$ and $\varphi$ and $\varphi^{\prime}$ are monotone in opposite senses.

As an example, let $a=0, b=\pi / 2, \varphi(x) \equiv \cos x . \varphi$ and $\phi^{\prime}$ are monotone in the same sense in $[0, \pi / 2]$, and $\varphi^{\prime \prime 2}=\cos ^{2} x>-\sin ^{2} x=$ $\varphi^{\prime} \varphi^{\prime \prime \prime}$ throughout $(0, \pi / 2)$. Therefore, $M_{-\sin x}<M_{\cos x}$, i.e., $M_{\sin x}<M_{\cos x}$.

6. In a previous paper [3] the authors studied, for given positive $q_{1}, q_{2}, \cdots, q_{n}$ (with $\sum_{\nu=1}^{n} q_{\nu}=1$ ), the ratio

$$
\left\{\begin{array}{l}
F\left(x_{1}, x_{2}, \cdots, x_{n}\right) \\
\quad=M_{x}\left(x_{1}, x_{2}, \cdots, x_{n} \mid q_{1}, q_{2}, \cdots, q_{n}\right) / M_{\psi^{\prime}}\left(x_{1}, x_{2}, \cdots, x_{n} \mid q_{1}, q_{2}, \cdots, q_{n}\right)
\end{array}\right.
$$

where $0<a, \psi(x) \equiv x^{r}, \chi(x) \equiv x^{s}(r<s, r s \neq 0)$.

Their purpose was to find an upper bound for $F$ in

$$
I=\left\{\left(x_{1}, x_{2}, \cdots, x_{n}\right): a \leqq x_{k} \leqq b, k=1,2, \cdots, n\right\} .
$$

A crucial step was to show that if $X^{*}$ is a point of $I$ such that $F\left(X^{*}\right)=\max \{F(X): X \in I\}$, then $X^{*}$ is necessarily a vertex of $I$. In particular, $X^{*}$ cannot be an interior point of $I$. This last property holds under quite general conditions:

THEOREM 6. Let $\psi$ and $\chi$ be elements of $\Phi$, differentiable in $(a, b)$, and satisfying $\psi^{\prime} \chi^{\prime} \neq 0$ there. Assume $0 \notin[a, b], \quad M_{\psi}<M_{x}$. Let $q_{1}, \cdots, q_{n}(n>1)$ be given positive numbers with $\sum_{\nu=1}^{n} q_{\nu}=1$, and let $I$ be as in the last paragraph. Let $F$ of (5) attain its maximum in $I$ at a point $X^{*}=\left(x_{1}^{*}, \cdots, x_{n}^{*}\right)$ of $I$. Then $X^{*}$ is not an interior point of $I$.

Proof. Suppose that some $x_{j}^{*}$ satisfies $a<x_{j}^{*}<b$. Then $\left(\partial F / \partial x_{j}\right)_{\substack{\nu=x_{\nu}^{*} \\ \nu=1,2, \cdots, n}}=0$, i.e.,

$$
\begin{gathered}
{\left[\psi^{-1}\left(\sum_{\nu=1}^{n} q_{\nu} \psi\left(x_{\nu}^{*}\right)\right)\right]^{-2}\left[q_{j} \chi^{\prime}\left(x_{j}^{*}\right) \psi^{-1}\left(\sum_{\nu=1}^{n} q_{\nu} \psi\left(x_{\nu}^{*}\right)\right) / \chi^{\prime}\left(\chi^{-1}\left(\sum_{\nu=1}^{n} q_{\nu} \chi\left(x_{\nu}^{*}\right)\right)\right)\right.} \\
\left.-q_{j} \psi^{\prime}\left(x_{j}^{*}\right) \chi^{-1}\left(\sum_{\nu=1}^{n} q_{\nu} \chi\left(x_{\nu}^{*}\right)\right) / \psi^{\prime}\left(\psi^{-1}\left(\sum_{\nu=1}^{n} q_{\nu} \psi\left(x_{\nu}^{*}\right)\right)\right)\right]=0 .
\end{gathered}
$$


Thus

$$
\begin{aligned}
\chi^{\prime}\left(x_{j}^{*}\right) / \psi^{\prime}\left(x_{j}^{*}\right)= & {\left[\chi^{-1}\left(\sum_{\nu=1}^{n} q_{\nu} \chi\left(x_{\nu}^{*}\right)\right) \chi^{\prime}\left(\chi^{-1}\left(\sum_{\nu=1}^{n} q_{\nu} \chi\left(x_{\nu}^{*}\right)\right)\right)\right] } \\
& \times /\left[\psi^{-1}\left(\sum_{\nu=1}^{n} q_{\nu} \psi\left(x_{\nu}^{*}\right)\right) \psi^{\prime}\left(\psi^{-1}\left(\sum_{\nu=1}^{n} q_{\nu} \psi\left(x_{\nu}^{*}\right)\right)\right)\right] .
\end{aligned}
$$

Let $C$ denote the right hand side of the last equality. If both $x_{j}^{*}$ and $x_{k}^{*}$ are interior points of $[a, b]$, then $\chi^{\prime}\left(x_{j}^{*}\right) / \psi^{\prime}\left(x_{j}^{*}\right)=C=\chi^{\prime}\left(x_{k}^{*}\right) / \psi^{\prime}\left(x_{k}^{*}\right)$, and hence, by the strict monotonicity of $\chi^{\prime} / \psi^{\prime}$ [see the end of $\S 2$ ], $x_{j}^{*}=x_{k}^{*}$. Thus, if $X^{*}$ were an interior point of $I$, we would have $x_{1}^{*}=x_{2}^{*}=\cdots=x_{n}^{*}$, and therefore

$$
1=F\left(x_{1}^{*}, x_{2}^{*}, \cdots, x_{n}^{*}\right)=\max \{F(X): X \in I\}>1 \text {. }
$$

\section{REFERENCES}

1. E. F. Beckenbach, On the inequality of Kantorovich (abstract), Notices, Amer. Math Society, 10, No. 5 (1963), 440.

2. E. F. Beckenbach and R. Bellman, Inequalities, Springer-Verlag (1961).

3. G. T. Cargo and O. Shisha, Bounds on Ratios of Means, Journal of Research of the National Bureau of Standards, Vol. 66B, No. 4, pp. 169-170 (1962).

4. G. H. Hardy, J. E. Littlewood, and G. Pólya, Inequalities (second edition), Cambridge University Press (1952).

5. H. Kestelman, Modern theories of integration (second revised edition), Dover Publications, 1960.

Aerospace Research Labolatories, Wright-Patterson AFB, Ohio AND

SYRACUSE UNIVERSITY 


\section{PACIFIC JOURNAL OF MATHEMATICS}

\section{EDITORS}

\author{
Robert Osserman \\ Stanford University \\ Stanford, California
M. G. Arsove
University of Washington
Seattle 5 , Washington

\author{
J. DugundJI \\ University of Southern California \\ Los Angeles 7, California
}

Lowell J. Paige

University of California

Los Angeles 24, California

\section{ASSOCIATE EDITORS}
E. F. BECKENBACH
B. H. NeumanN
F. WOLF
K. YOSIDA

\section{SUPPORTING INSTITUTIONS}

\author{
UNIVERSITY OF BRITISH COLUMBIA \\ CALIFORNIA INSTITUTE OF TECHNOLOGY \\ UNIVERSITY OF CALIFORNIA \\ MONTANA STATE UNIVERSITY \\ UNIVERSITY OF NEVADA \\ NEW MEXICO STATE UNIVERSITY \\ OREGON STATE UNIVERSITY \\ UNIVERSITY OF OREGON \\ OSAKA UNIVERSITY \\ UNIVERSITY OF SOUTHERN CALIFORNIA
}

\author{
STANFORD UNIVERSITY \\ UNIVERSITY OF TOKYO \\ UNIVERSITY OF UTAH \\ WASHINGTON STATE UNIVERSITY \\ UNIVERSITY OF WASHINGTON \\ * * * * \\ AMERICAN MATHEMATICAL SOCIETY \\ CALIFORNIA RESEARCH CORPORATION \\ SPACE TECHNOLOGY LABORATORIES \\ NAVAL ORDNANCE TEST STATION
}

Mathematical papers intended for publication in the Pacific Journal of Mathematics should by typewritten (double spaced), and on submission, must be accompanied by a separate author's résumé. Manuscripts may be sent to any one of the four editors. All other communications to the editors should be addressed to the managing editor, L. J. Paige at the University of California, Los Angeles 24, California.

50 reprints per author of each article are furnished free of charge; additional copies may be obtained at cost in multiples of 50 .

The Pacific Journal of Mathematics is published quarterly, in March, June, September, and December. Effective with Volume 13 the price per volume (4 numbers) is $\$ 18.00$; single issues, $\$ 5.00$. Special price for current issues to individual faculty members of supporting institutions and to individual members of the American Mathematical Society: $\$ 8.00$ per volume; single issues $\$ 2.50$. Back numbers are available.

Subscriptions, orders for back numbers, and changes of address should be sent to Pacific Journal of Mathematics, 103 Highland Boulevard, Berkeley 8, California.

Printed at Kokusai Bunken Insatsusha (International Academic Printing Co., Ltd.), No. 6, 2-chome, Fujimi-cho, Chiyoda-ku, Tokyo, Japan.

PUBLISHED BY PACIFIC JOURNAL OF MATHEMATICS, A NON-PROFIT CORPORATION

The Supporting Institutions listed above contribute to the cost of publication of this Journal, but they are not owners or publishers and have no responsibility for its content or policies. 


\section{Pacific Journal of Mathematics}

\section{Vol. 14, No. $3 \quad$ July, 1964}

Erik Balslev and Theodore William Gamelin, The essential spectrum of a class of ordinary differential operators . . . . . . . . . . . . . . . . . . . .

James Henry Bramble and Lawrence Edward Payne, Bounds for derivatives in

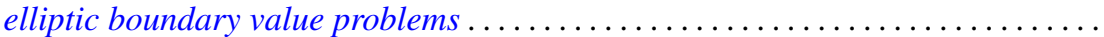

Hugh D. Brunk, Integral inequalities for functions with nondecreasing

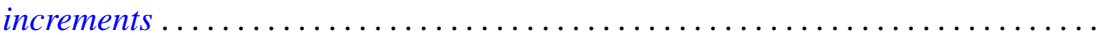

William Edward Christilles, A result concerning integral binary quadratic

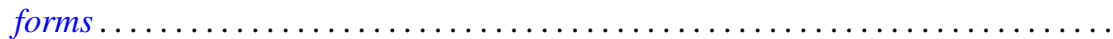

Peter Crawley and Bjarni Jónsson, Refinements for infinite direct decompositions of

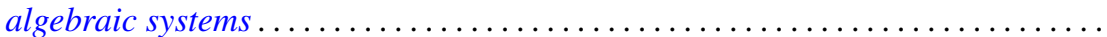

Don Deckard and Carl Mark Pearcy, On continuous matrix-valued functions on a Stonian space.

Raymond Frank Dickman, Leonard Rubin and P. M. Swingle, Another

characterization of the $n$-sphere and related results $\ldots \ldots \ldots \ldots \ldots \ldots$

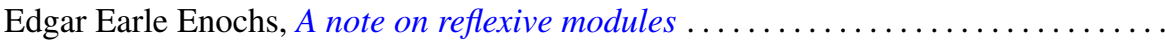

Vladimir Filippenko, On the reflection of harmonic functions and of solutions of the

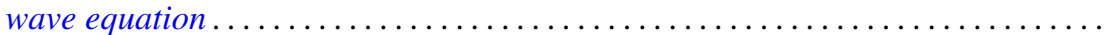

Derek Joseph Haggard Fuller, Mappings of bounded characteristic into arbitrary

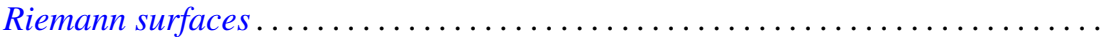
895

Curtis M. Fulton, Clifford vectors . . . . . . . . . . . . . . . . . . . . . . . . . . . . . . 917

Irving Leonard Glicksberg, Maximal algebras and a theorem of Radó . .

919

Kyong Taik Hahn, Minimum problems of Plateau type in the Bergman metric

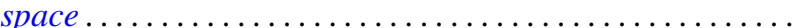

A. Hayes, A representation theory for a class of partially ordered rings...

J. M. C. Joshi, On a generalized Stieltjes trasform

J. M. C. Joshi, Inversion and representation theorems for a generalized Laplace transform ...

Eugene Kay McLachlan, Extremal elements of the convex cone $B_{n}$ of functions ...

Robert Alan Melter, Contributions to Boolean geometry of p-rings ...

James Ronald Retherford, Basic sequences and the Paley-Wiener criterion . . . . . . . 1019

Dallas W. Sasser, Quasi-positive operators. .

Oved Shisha, On the structure of infrapolynomials with prescribed coefficients ..

Oved Shisha and Gerald Thomas Cargo, On comparable means

Maurice Sion, A characterization of weak ${ }^{*}$ convergence ........

Morton Lincoln Slater and Robert James Thompson, A permanent inequality for

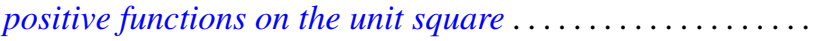

David A. Smith, On fixed points of automorphisms of classical Lie algebras ...

Sherman K. Stein, Homogeneous quasigroups ................

J. L. Walsh and Oved Shisha, On the location of the zeros of some infrapolynomials with prescribed coefficients .

Ronson Joseph Warne, Homomorphisms of $d$-simple inverse semigroups with identity . 